\title{
ACCOUNTING METHODS OF THE OPERATIONS PERFORMED FOR THE REORGANISATION OF COMPANIES
}

\author{
Deju Mihai \\ "Vasile Alecsandri" University of Bacău \\ mihai.deju@ub.ro
}

\begin{abstract}
The process of company reorganisation by merger or division operations, which is the object of recent accounting regulations, are of a real interest for the accounting specialists, taking into consideration the elements of newness and the complexity of financial-accounting operations. In this article, we aim to present the particularities of the specific accounting methods of the operations performed for the reorganisation of companies.
\end{abstract}

Keywords:

merger; reorganisation; methods; accounting

\section{JEL Classification}

M41

Merger operations involve the transfer of assets, debts and equity items from one or more companies to another company, which will issue and allocate the shares to the shareholders/associates of the companies that dissolve on the basis of the exchange ratio agreed by the companies involved in the merger.

The exchange ratio, which is at the basis of the pay of the merger contribution of the company being acquired, can be determined on the basis of net accounting asset, based on the accounting balance sheets prepared on the occasion of a merger or on the basis of the non-accounting balance sheets, which there can be found the adjustments arising from the evaluation of the balance sheet by the evaluators.

At the recording in accounting of the reorganisation operations through merger, there will be taken into account a series of rules of a general nature:

- the participating companies to the merger operation will be drawn up in accordance with the legislation in force ${ }^{1}$, financial statements with a special purpose (merger) for the set date in accordance with the commercial companies law ${ }^{2}$ and which will be submitted to the territorial units of the MFP within 30 days of their approval by the General meetings of the respective companies;

- the recording in accounting of the main operations on the reorganisation through merger of companies, will be performed in compliance with accounting rules and the specific accounting regulations ${ }^{3}$, with European directives or to international financial reporting standards (IFRS), as appropriate.

Where the companies involved in the same operation apply different accounting regulations compliant with European directives or regulations, which comply with

\footnotetext{
1 Accounting Law nr.82/91 republished in Monitorul oficial of Romania, nr.454/2008, with further amendments and completions, art.28, alin $1^{\wedge} 1$.

${ }^{2}$ Companu Law, nr.31/90 with further amendments and completions, art.244

${ }^{3}$ OMFP nr. 897/2015 for the approval of Methodological Norms concerning the recording in accounting of the main operations of merger, division, dissolution and close-out of companies, as well as the withdrawal or exclusion of some associates from the companies, with further amendments and completions.
} 
IFRS, the accounting treatment of the merger operations is that foreseen by the accounting regulations applicable to each entity;

- in the financial statements afferent to the merger, the companies involved will also take over the results of the inventory and the evaluation occasioned by the operation of reorganisation through merger, according to the applicable legal regulations. Thus, according to pt. 101 of the accounting regulations concerning annual financial statements and consolidated annual financial statements, approved by OMFP no. $1802 / 2014$ "the assessments made in connection with the reorganisation of companies (mergers, divisions) do not constitute a reassessment in the meaning of these regulations, such assessments are being carried out in order to determine the exchange ratio for all items of the balance sheet. There make exception the cases when the date of financial statements that are at the basis of the reorganisation coincides with the date of the annual financial statements";

- from a fiscal point of view, companies that are reorganised, including by merger operations, must comply with the provisions of law 227/2015 regarding the Fiscal Code, with subsequent amendments and additions, the law governing matters relating to the procedure for carrying out such operations, as well as any other regulations governing aspects of a fiscal nature, in effect on the date of reorganisation;

- the shares held by companies that are being reorganised, one in the capital of the other (mutual holding), will cancel, at book value, on account of the elements of equity laid down by the general meeting of shareholders/associates. Where there is sufficient equity to cover the value of the cancelled shares, the difference will be supported from the results of the merger - account 149.5 "Losses arising from the reorganisation, which are determined by the cancelling of titles held". These losses will be covered from profit or other equity items, as decided by shareholders/associates in the General Meeting;

- the transfer from the company being acquired/companies that end their activity to the acquiring/newly founded company, of assets, debts and equity shall be effected on the basis of delivery-receipt protocols concluded between the receiving company and the company/companies that deliver the merger contribution;

- in the delivery-receipt protocol there will be indicated, for each company being acquired/companies that end their activity, the balance accounts according to the checking balances that were at the basis of the financial statements drawn up for the merger operation, as well as other information necessary for the entry into the accounts of acquired elements. In the accounting of the acquiring company/newly founded company, there will be taken account balances of the company being acquired/companies that end their activity, to the values specified in the deliveryreceipt protocol.

Simultaneously with the transfer of goods and the values from the company being acquired to the acquiring company there will also be delivered the documents confirming the ownership right on the intake transferred;

- in the delivery-receipt protocol concluded between the companies participating in the merger there will also be written the result recorded in the "profit or loss account", by the company being acquired/companies that end their activity, during the period between the date when the financial statements were drawn up related to the merger and the date of delivery-receipt protocol. The result of this period will be taken by the acquiring company/newly founded company through account 117 "Result brought forward"-analytically distinct;

- in the delivery-receipt protocol of patrimonial items transferred in connection with the merger there will be written clear data relating to assets, liabilities, equity with the specification of their tax value;

- the determination of the exchange ratio and the merger premium will be in accordance with General Assembly decision of shareholders/members of the 
companies involved in the merger, based on accounting balance sheets incurred in the operation of merger - in the case of using the net asset accounting method or on the basis of the non-accounting balance sheets - when using the global assessment method, which will also include adjustments (differences) resulting from the assessment made by the evaluators.

Depending on how is determined the value of net merger contribution of companies involved in the reorganisation operation through merger, from an accounting point of view, there can be used two methods for recording the merger transactions, i.e. the net asset method, or the global assessment method, respectively.

As follows, there will be presented particularities concerning the accounting recording of the reorganisation operation through merger of companies, in the case of using the net accounting asset for the determination of the net merger contribution.

The net asset accounting method assumes that the values used in the reorganisation operations through merger are based on the use of net accounting asset, determined as difference between total assets and total liabilities reflected in balance sheets related to the merger. The accounting net assets established this way corresponds to equity.

In the case of using the net asset accounting method, for the recording in accounting of the reorganisation operations through merger, there will be taken into account the following rules:

- the assets, liabilities, and equity of the company being acquired/companies that end their activity, are removed from their records at the existing value in accounting;

- the recognition in the accounts the acquiring company/newly founded company of assets transferred from the company being acquired/companies that end their activity is accomplished at the net accounting value or the gross accounting value, case when there are taken distinctly their afferent adjustments, as they are emphasised in the accounting of the company being acquired/companies that end their activity as a result of the merger;

- the recording in the accounts of the acquiring company/newly founded company of balance sheet items constituting the merger contribution is based on the balances of the synthetic checking accounts, analytical checking balances and other accounting documents (journals, books, etc.) that were at the basis of the financial statements related to the merger and recorded in the delivery-receipt protocol between companies involved in the operation;

- the recording of the net merger contribution, on the equity items by the acquiring company is made in accordance with the merger project approved by the General Assemblies of the companies involved in the operation;

- from an accounting point of view, the merger transactions are treated distinctly depending on the specifics of the merger operation, namely the merger by absorption or merger by reunion.

\section{A. The merger by absorption}

I. Entries in the accounts of the acquiring company:

1. the entry of the registered capital increase and the merger premium:

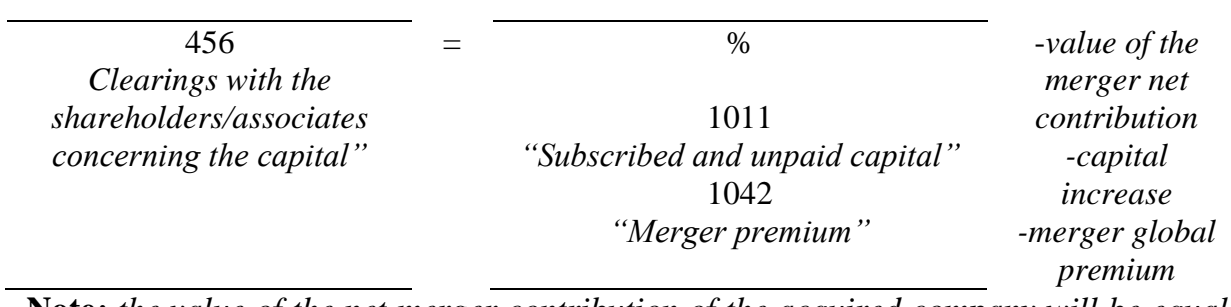

Note: the value of the net merger contribution of the acquired company will be equal to the net accounting asset established within the merger. 
2. The entry of the take-over by transfer, in accordance with the delivery-receipt protocol of assets elements:

\begin{tabular}{cc}
\hline$\%$ & $=$ \\
"Accounts of assets elements $* *$ & 891 \\
&
\end{tabular}

Note: There will be taken at the net or gross value as they were written in the delivery-receipt protocol. If they are taken at the gross value, then there will also be taken the appropriate adjustments and depreciations.

3. The entry of the take-over by transfer, in accordance with the delivery-receipt protocol of the liabilities, amortization and adjustments afferent to the balance sheet items transferred at gross value:

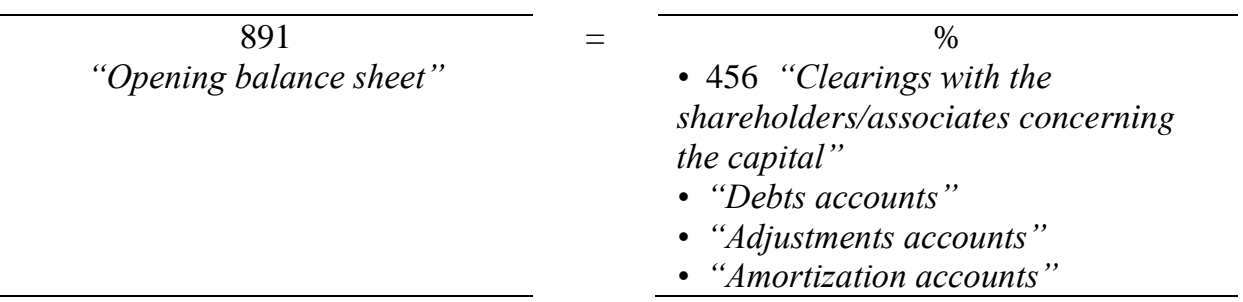

II. Entries in the accounts of the company being acquired:

1. The taking from the accounting records of the equity elements and the recording of shareholders/associates' rights concerning the remuneration of the merger contribution:

\begin{tabular}{ccc}
\hline$\%$ & $=$ & 456 \\
"Equity accounts" & $\begin{array}{c}\text { "Clearings with the shareholders/ } \\
\text { associates concerning the capital" }\end{array}$ \\
\hline
\end{tabular}

2. The taking from the records of transferred assets elements:

\begin{tabular}{cc}
\hline 892 & $\%$ \\
"Closing balance sheet" & $\%$ \\
\hline
\end{tabular}

*Note: With the balances with which the assets elements accounts were recorded in the delivery-receipt protocol, at net or gross value, case in which the afferent amortizations and adjustments will be transferred.

3. The taking from the records of the transferred elements, as liabilities, amortizations and adjustments of the transferred assets.

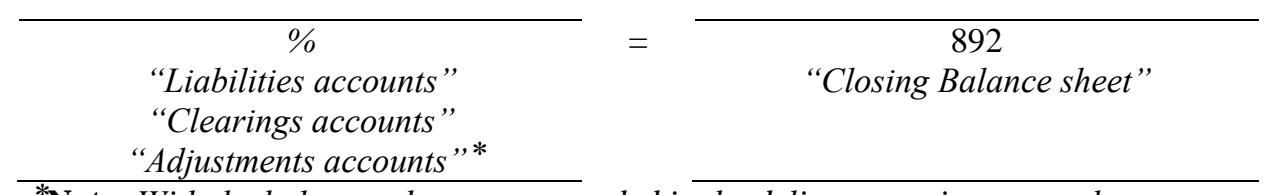

*Note: With the balances that were recorded in the delivery-receipt protocol. 
4. The regularisation of accounts 456 "Clearings with the shareholders/associates concerning the capital" and 892 "Closing Balance Sheet", respectively the discharge of obligations concerning the remuneration of shareholders/associates for the merger contribution:

\begin{tabular}{cc}
\hline 456 & $=$ \\
"Clearings with the shareholders/ \\
associates concerning the capital"
\end{tabular}

Instead of the entries at p.4, there could be reflected the receivable rights of shareholders/associates concerning the merger contribution transferred through the accounting article:

\begin{tabular}{cc}
\hline 461 \\
"Different debtors"
\end{tabular}

and the discharge of receivables by receiving shares from the acquiring company and their repartition to the shareholders/associates of the acquired company:

\begin{tabular}{|c|c|c|}
\hline $\begin{array}{c}456 \\
\text { "Clearings with the shareholders/ } \\
\text { associates concerning the capital" }\end{array}$ & $=$ & $\begin{array}{c}461 \\
\text { "Different debtors" }\end{array}$ \\
\hline
\end{tabular}

\section{B. The merger by reunion}

I. Entries in the accounts of the newly set company:

1. The entry of the constitution of the registered capital, by the contribution of companies that are being dissolved $(\mathrm{A}$ and $\mathrm{B})$ :

\begin{tabular}{c}
\hline 456 \\
$\begin{array}{c}\text { "Clearings with the shareholders/ } \\
\text { associates concerning the capital" }\end{array}$ \\
$\begin{array}{c}\text { "Subscribed and paid capital" } \\
\text { analytically: Company A } \\
\text { Company B }\end{array}$ \\
\hline
\end{tabular}

\section{Note:}

I mention the fact that in the case of the merger by reunion there are no merger premiums, as the beneficiary society is newly set up and the nominal value of the issued shares is that set by the merger project.

2. The take-over from the companies that are being dissolved of assets elements:

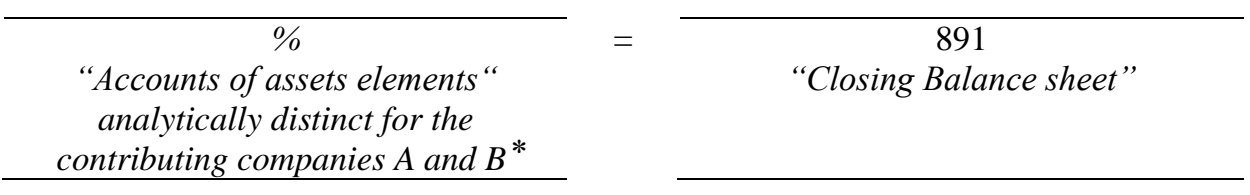

*Note: with the balances that were recorded in the delivery-receipt protocol.

3. The take-over from the dissolving companies of liabilities, amortizations, adjustments afferent to the transferred balance sheet elements: 
$891+=$

"Opening Balance sheet"
$=$

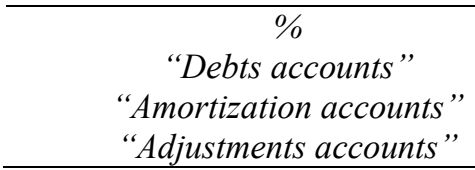

*Note: with the balances that were recorded in the delivery-receipt protocol.

II. Entries in the accounts of the dissolving companies:

- the entries are similar to the ones made by the company being acquired in the case of the merger by absorption, thus:

1. The taking from the records of equity elements and the recording of the shareholders/associates rights concerning the remuneration of the merger contribution:

$\%$
"Equity accounts"

\section{6}

"Clearings with the shareholders/ associates concerning the capital"

2. The cut from the records of transferred asset elements:

\begin{tabular}{cc}
\hline 892 & $\%$ \\
"Closing Balance sheet" & $\%$ \\
\hline
\end{tabular}

*Note: With the balances with which the assets elements accounts were recorded in the delivery-receipt protocol.

3. The taking from the records of the transferred elements, as liabilities, clearings and adjustments afferent to the transferred assets.:

\begin{tabular}{cc}
\hline$\%$ & $=$ \\
"Debts accounts" & 892 \\
"Amortization accounts" & "Closing Balance sheet" \\
\hline
\end{tabular}

*Note: with the balances that were recorded in the delivery-receipt protocol.

4. The regularisation of accounts 456 "Clearings with the shareholders/associates concerning the capital" and 892"Closing Balance", respectively the discharge of obligations concerning the remuneration of shareholders/associates for the merger contribution:

\begin{tabular}{|c|}
\hline $\begin{array}{l}456 \\
\text { "Clearings with the shareholders/, } \\
\text { associates concerning the capital" }\end{array}$ \\
\hline
\end{tabular}

Instead of the entries at p.4, there could be reflected the receivable rights of shareholders/associates concerning the merger contribution transferred through the accounting article: 


\begin{tabular}{cc}
\hline 461 & $=$ \\
"Different debtors" & 892 \\
\end{tabular}

and the discharge of receivables by receiving shares from the acquiring company and their repartition to the shareholders/associates of the acquiring company:

\begin{tabular}{cc}
\hline 456 & $=$ \\
$\begin{array}{c}\text { "Clearings with the shareholders/ } \\
\text { associates concerning the capital" }\end{array}$ & "Different debtors" \\
\hline
\end{tabular}

\section{Conclusions}

The companies involved in the reorganisation operations through merger establish, by decisions of the General meetings of each of the companies involved, the conditions of the merger, the way of establishing the net intake of merger and exchange ratio underlying the remuneration of shareholders/members of the disbanded companies/the companies being acquired.

If the exchange ratio will be determined based on the value of net merger contribution, established on the basis of the net assets of each company involved in the merger, for the recording of merger operations, from accounting point of view, there will be used the net asset accounting method as described throughout this paper. In other cases, where the value of merger contribution differs from the net asset value, there will be used for the accounting recording of merger operations, the method of global evaluation, which will be the subject of other research topics concerning its use in the accounting practice.

\section{References}

Deju, M. (2013), Contabilitate aprofundată - curs universitar, Bacău, Editura Alma Mater.

Accounting Law $n r$. 82/1991, republished in Monitorul Oficial nr.454/2008, with further amendments and completions.

Company Law nr. 31/1990, republished in Monitorul Oficial, Partea I, nr. 1066 din 17 November 2004, with further amendments and completions.

Order nr. 1802 from 29 December 2014, for the approval of Accounting Regulations on annual individual financial statements and annual consolidated financial statements published in Monitorul Oficial nr. 963 din 30 December 2014, with further amendments and completions.

OMFP nr.1286/ from $1^{\text {st }}$ October 2012, for the approval of Accounting Regulations in accordance with International Standards of financial report, for commercial companies whose real-estate value are admitted on a regulated market, published in Monitorul Oficial nr. 687 din 4 October 2012, with further amendments and completions.

OMFP $n r$. 897/2015 for the approval of Methodological Norms concerning the recording in accounting of the main operations of merger, division, dissolution and close-out of companies, as well as the withdrawal or exclusion of some associates from the companies, with further amendments and completions. 